\title{
Is Early Surfactant Administration Associated with Reduced Mortality in the Late Preterm Infant?
}

\section{AJ Van Heerden*}

\begin{abstract}
Background: The late preterm infant is at great risk of neglect because it is perceived as near term, however this group suffers from disease due to prematurity and needs great attention. Surfactant use is a well-established intervention that improves outcomes in preterm infants however the timing of its use in this group is not well studied.

Objective: To assess whether administration of surfactant within $30 \mathrm{~min}$ of birth when clinically indicated reduces mortality in the late preterm infant, and to compare rates of early surfactant use and mortality to international trends using the Vermont Oxford Network database.

Methods: This was a retrospective study conducted at private neonatal ICU in Gauteng, where data were collected from 2002 to 2013. Data on mortality and surfactant use were compiled using the online database called the Vermont Oxford Network. Comparisons were then made between the periods where surfactant was administered early and when they were not.

Results: A total of 3040 cases were retrieved over the study period 2002 to 2013. The mean age of the population was 35-1/7 weeks and the mean birth weight was 2222.32 grams. During the study period, early surfactant administration rose to $90.62 \%$ compared to the VON which was averaged at $32.53 \%$. Mortality dropped from $3.12 \%$ to $0.39 \%$ during the interventional period. This was significantly lower than the VON's mortality of $1.21 \%(\mathrm{p}<0.05)$. A strong inverse correlation between early surfactant use and mortality was observed with the Pearson correlation coefficient being $-0.86(\mathrm{p}<0.05)$.

Conclusion: This study showed that for the late preterm infant, early surfactant use within 30 minutes of birth was significantly higher at the study center than international trends. It also demonstrated that mortality was lower, and that a strong inverse correlation was found between mortality and early surfactant use. Being a retrospective study, there is the possibility of confounding variables, and so a Double blind controlled study is needed to explore the timing of surfactant administration in the late preterm infant.
\end{abstract}

\section{INTRODUCTION}

Late preterm infants, defined by gestational age of $34-0 / 7$ to $36-6 / 7$ weeks, make up the largest proportion of the preterm group [1]. The late preterm infant may be thought of as the "forgotten prem", having comparatively fewer studies done on the group and having sometimes been managed like a term infant.
Although they are near to term infants, they have been shown to suffer a threefold increase in mortality when compared to term infants [2]. As for morbidity, these infants are more likely to experience hypothermia, hypoglycaemia, hyperbilirubinemia, respiratory disease, intraventricular haemorrhage, necrotizing enterocolitis, and sepsis [3]. All of these morbidities contribute to the higher mortality rate of the late preterm infant when compared to term infants.

Sandton Mediclinic Hospital, Neonatal ICU, South Africa

Received date: January 03, 2019; Accepted date: January 21, 2019; Published date: January 28, 2019

Citation: Heerden AJV. Is early surfactant administration associated with reduced mortality in the late preterm infant? Clinics Mother Child Health. 2019;16:314. doi:10.24105/2090-7214.1000314

Copyright: (C) 2019 Heerden AJV. This is an open-access article distributed under the terms of the Creative Commons Attribution License, which permits unrestricted use, distribution, and reproduction in any medium, provided the original author and source are credited. 
Surfactant use is an established and well-studied treatment of respiratory distress syndrome (RDS) in prematurity, and research on preterm and very preterm infants have demonstrated that early surfactant use is beneficial [4]. However the timing of its administration in the late preterm infant has not been explored as much and it is also thought that the pathogenesis of respiratory distress syndrome in this particular group may be different [5]. We are of the opinion that surfactant should be given early within 30 minutes of birth if indicated clinically. We do not advocate prophylactic surfactant use in the late preterm infant. From 2005 this concept was put into clinical practice in the unit.

Data from the neonatal unit (reference unit-RU) were collected on the Vermont Oxford Network (VON) which is a group of over 900 international neonatal ICUs. This network not only allows effective data collection and analysis but also allows for comparison. The large subscription base of the network approximates an international norm.

The objective of this study is to demonstrate how the RU has moved to administer surfactant promptly within 30 min of birth if indicated, and to try correlating this with mortality rates. The study will also compare the RUs results to that of the VON.

\section{METHODS}

This was a retrospective study covering the period 2002 to 2013, and data was drawn from the Vermont Oxford Network (VON), which is an international database of neonatal ICU where participants can upload and share outcomes data from their centers. The setting is a private neonatal ICU in Gauteng, South Africa. All late preterm infants admitted to the unit were included in the study. Patients were grouped into "early surfactant use" if they received surfactant within $30 \mathrm{~min}$ of birth, and they had a clinical need for its use. Mortality rates were also gathered from the VON for the study period. Early surfactant use and mortality were correlated using the Pearson correlation coefficient, and significance was tested using the student $t$ test. Differences in rates of mortality and early surfactant use between periods were also analyzed and tested for statistical significance.

\section{RESULTS}

The number of patients in the study over the 12 year period was 3964 , and the mean birth weight was $2220.32 \mathrm{~g}$. The mean gestational age of the group was 35-1/7. The average age of the mother was 26, and antenatal care at the clinic includes consistent steroid use (this policy has not changed over the period). There were no exclusion criteria (e.g. syndromic infants), in that all preterm infants admitted to the unit were included. Unfortunately no data on maternal morbidity (Diabetes, Eclampsia etc.) were collected.

Figure 1 shows the percentage of infants who received early surfactant over the study period. $90.62 \%$ of infants who needed surfactant received it within 30 min of birth from 2005 to 2013. The centers of the VON administered early surfactant in 32.53 $\%$ of cases. There was a statistically significant difference between the reference unit and the VON in this regard $(p<0.05)$.

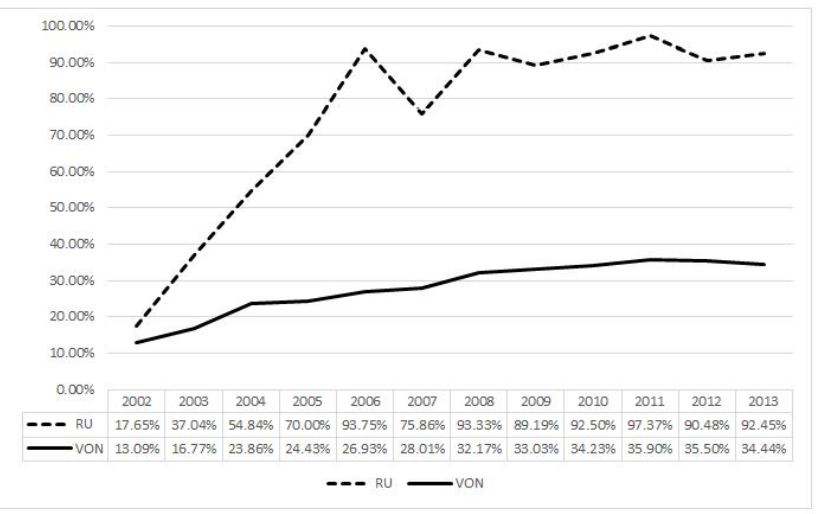

Figure 1: Percentage of late preterm infants receiving early surfactant.

Figure 2 shows the mortality rates for late preterm infants in the study period, with a significant reduction from 2005. Average mortality rate from 2005 to 2013 was $0.39 \%$ and $1.21 \%$ for the RU and the VON respectively. There was a statistically significant difference between these data groups $(\mathrm{p}<0.05)$.

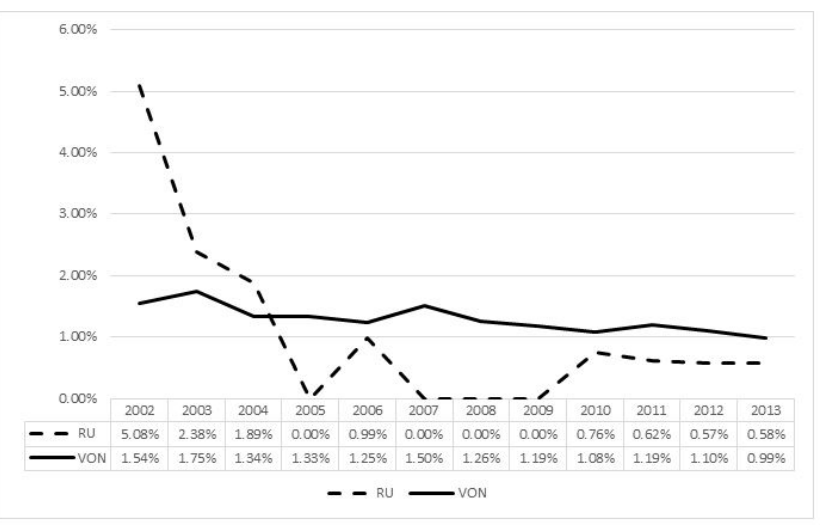

Figure 2: Mortality rates for late preterm infants.

There was a strong inverse correlation between mortality and early surfactant use with Pearson correlation coefficient being -0.86 , and this result was statistically significant $(\mathrm{p}<0.05)$.

\section{DISCUSSION}

The late preterm infant group is unique in that they have often been expected to behave like term infants. Although few studies have been made specifically for this group, a systematic review concluded from controlled clinical trials that improved mortality rates in preterm infants were observed for early selective surfactant administration [6]. Our study has observed similar results in specifically the late preterm group.

A strong inverse correlation was observed between mortality and the administration of early surfactant use for the late preterm infant group. The reference unit's use of early surfactant was significantly higher than the VON and the mortality rates lower, which coincided with the change in policy of its use.

The weakness of this study is that there were other factors at play during the study, such as nasal CPAP use, which could confound the data. A retrospective study of this kind does can highlight a possible link but a double blind control study will be needed. Another criticism is that it may be argued that the early 
use of surfactant may in some cases equate to prophylactic use, and strict indications for early selective surfactant administration must be developed.

There is little knowledge on the optimum timing of surfactant use in the late preterm infant, and this study suggests that early selective use may improve outcomes. It may be that prophylactic use of surfactant will provide even better results, however this must be weighed against the cost of its use.

\section{CONCLUSION}

The late preterm infant has possibly been neglected in the past and may need more aggressive treatment to reduce mortality. In the world of ever increasing costs the use of a financially expensive intervention must be used responsibly. This study suggests that reduced mortality rates could be observed by administering surfactant within $30 \mathrm{~min}$ of birth if clinically indicated. Further studies are needed to explore this concept.

\section{ETHICS APPROVAL}

Ethics approva. 1 for the study was obtained from the Hospital Ethics Research Committee.

\section{REFERENCES}

1. Goldenberg RL, Culhane JF, Iams JD, Romero R. Epidemiology and causes of preterm birth. Lancet. 2008;371:75-84.

2. Tomashek KM, Shapiro-Mendoza CK, Davidoff MJ, Petrini JR. Differences in mortality between 7. late-preterm and term singleton infants in the United States, 1995-2002. Pedia. 2007;151:450-456.

3. McIntire DD, Leveno KJ. Neonatal mortality and morbidity rates in late preterm births compared with births at term. Obstet Gynecol. 2008;111:35-41.

4. Stritzke A, Mohammad K, Shah PS, Ye XY, Bhandari V. Use and timing of surfactant administration: Impact on neonatal outcomes in extremely low gestational age infants born in Canadian Neonatal Intensive Care Units. J Matern Fetal Neonatal Med. 2018;31:1-8.

5. Sürmeli-Onay O, Korkmaz A, Yiğit S, Yurdakök M. Surfactant therapy in late preterm infants: respiratory distress syndrome and beyond. Turk J Pediatr. 2012;54:239-246.

6. Bahadue FL, Soll R. Early versus delayed selective surfactant treatment for neonatal respiratory distress syndrome. Cochrane Database Syst Rev. 2012;11:CD001456. 